\title{
Student Seminars in Basic Medical Sciences: Perception of First Year Dental Students
}

\author{
Kumar Goothy SS${ }^{1}$, Srilatha B $^{2 *}$, Swathi Movva ${ }^{2}$, Manyam R $^{3}$ and \\ Avinash Prasad $\mathrm{Y}^{4}$ \\ ${ }^{1}$ Department of Physiology, Vishnu Dental College, India \\ 2Department of Bio-Chemistry, Vishnu Dental College, India \\ ${ }^{3}$ Department of Oral Pathology, Vishnu Dental College, India \\ ${ }^{4}$ First Year BDS student, Vishnu Dental College, India
}

*Corresponding author: Srilatha B, Assistant Professor, Department of Bio-Chemistry, Vishnu Dental College, Bhimavaram, West Godavari District, Andhra Pradesh, India, Email: srilathab@vdc.edu.in

\begin{abstract}
Medical education is changing drastically from teacher centered learning to active learning. Seminars promote active learning as it involves the student actively to go through various study materials to prepare to deliver the seminar effectively. A total of 70 male and female participants were part of the study after obtaining the written informed consent. Seminars were included as a weekly activity in the Department of Physiology. Thrust areas were identified in each system and topics were allotted to the students. 5 students were given opportunity to present the seminar in a week according to their role numbers. They were given 8 minutes to present the topic and 2 minutes for discussion. After the presentation the questions which are not answered were noted down and they were explained by the facilitator in the tutorials where all the 70 students were present. The same day, students were requested to provide the feedback about their perceptions on Likert four point scale. Majority of the students had given positive response to the seminars. The study recommends the inclusion of weekly seminars in the dental curriculum.
\end{abstract}

Keywords: Seminars; Dental students; Physiology

\section{Introduction}

Medical education is changing drastically from teacher centered learning to active learning. Seminars promote active learning as it involves the student actively to go through various study materials to prepare to deliver the seminar effectively. Further, it improves the communication skills of the students which are important in medical and dental professions. Seminars also help in improving the self-learning skills of the students [1].
Physiology deals with the study of normal functioning of body systems. Understanding Physiology is most essential in dentistry as it helps not only to understand other subjects but also helps to analyze and apply the knowledge [2,3]. Seminar preparation ensures the students to improve their skills of note making and interpersonal relationships. The presentation of seminars helps them to improve their communication skills so that they come out of the social inhibitions in public talking [4]. Further, they have to refer many resources that 


\section{International Journal of Biochemistry \& Physiology}

include the online and offline resources which make them to understand and integrate the concepts in physiology. After the seminar, the discussion sessions where the audience asks the questions to the presenter will also help to understand the subject thoroughly and effectively [5]. The present study was undertaken to observe the perception of first year dental students about seminars in basic medical sciences.

\section{Materials and Methods}

Study Design: Observational study.

Study Setting: The present study was conducted at Department of Physiology, Vishnu dental college, Bhimavaram.

Study Participants: A total of 70 male and female participants were part of the study after obtaining the written informed consent. Healthy participants, studying first year BDS course and willing to participate were included in the study.

\section{Physiology Seminars}

Seminars were included as a weekly activity in the Department of Physiology. Thrust areas were identified in each system and topics were allotted to the students. 5 students were given opportunity to present the seminar in a week according to their role numbers. As we follow the small group teaching pattern, total 70 students were randomly divided into three groups. Each week 15 students were presented the seminars. The topics per week and facilitators list were notified to the students through displaying in the notice boards of the department as well as through what's up group where all the faculty of physiology and first year students were present. Students were instructed to present the seminar through Power point or using black board according to their comfort. Soon after the topic allotment, they discussed with their facilitator about the preparation of content for presentation. After the discussion session they prepared the content and collected the inputs from the facilitators. They were given 8 minutes to present the topic and 2 minutes time for discussion. After the presentation the questions which are not answered were noted down and they were explained by the facilitator in the tutorials where all the 70 students were present. The same day, students were requested to provide the feedback about their perceptions on Likert four point scale.

\section{Ethical Considerations}

The present study was approved by institutional research committee of Vishnu Dental College, Bhimavaram.

\section{Data Analysis}

Data was analyzed by using SPSS 20.0 version (IBM). Data was expressed as frequency and percentage.

\section{Results}

$42 \%$ of the students reported that their enthusiasm about the presentation was good. $39 \%$ of students reported that faculty guides help to you while preparing for this seminar was good. 39\% of the students reported that respect shown by the faculty for your idea was good.

\begin{tabular}{|c|c|c|c|c|}
\hline \multirow{2}{*}{ Question } & Excellent & Good & Fair & Poor \\
\cline { 2 - 5 } & $\mathbf{F ~ ( \% )}$ & $\mathbf{F ~ ( \% )}$ & $\mathbf{F ~ ( \% ) ~}$ & F (\%) \\
\hline Your enthusiasm about the presentation was & $28(40)$ & $42(60)$ & $0(0)$ & $0(0)$ \\
\hline The faculty guides help to you while preparing for this seminar was & $29(41.4)$ & $39(55.7)$ & $2(2.9)$ & $0(0)$ \\
\hline The respect shown by the faculty for your idea was & $30(42.9)$ & $39(55.7)$ & $1(1.4)$ & $0(0)$ \\
\hline The way you develop analytical and synthesis skill was & $30(42.9)$ & $38(54.3)$ & $2(2.9)$ & $0(0)$ \\
\hline Your coverage of the given topic was & $26(37)$ & $40(57.1)$ & $3(4.3)$ & $1(1.4)$ \\
\hline The way you organized and timed your presentation was & $20(28.6)$ & $42(60)$ & $7(10)$ & $1(1.4)$ \\
\hline The audio visual aids you used were & $17(24.3)$ & $44(62.9)$ & $8(11.4)$ & $1(1.4)$ \\
\hline Your outline of the seminar was & $23(32.9)$ & $45(64.3)$ & $2(2.99)$ & $0(0)$ \\
\hline On the whole seminar was & $25(35.7)$ & $45(64.3)$ & $0(0)$ & $0(0)$ \\
\hline On the end of the seminar your self -esteem was & $23(32.9)$ & $42(60)$ & $4(5.7)$ & $1(1.4)$ \\
\hline
\end{tabular}

Table 1: Students feedback.

$38 \%$ of students reported that way they develop analytical and synthesis skill was good. $40 \%$ of the students reported that their coverage of the given topic was good. $42 \%$ of the students reported that the way they have organized and timed their presentation was good. $44 \%$ of the students reported that the audio visual aids 


\section{International Journal of Biochemistry \& Physiology}

you used were good. $45 \%$ of the students reported that their outline of the seminar was good. $45 \%$ of the students were reported that on the whole seminar was good. $42 \%$ of the students reported that at the end of the seminar their self -esteem was improved.

\section{Discussion}

The present study was undertaken to observe the advantages of seminars as learning tool under student centric method of teaching. It showed that seminar made the students to understand the concepts in a much better way as they learned the topic assigned in detail before presenting it in the class [6]. The learning was facilitated by the mentors and briefly discussed. The concept oriented learning was the reason behind the results of improvement not just in gaining the knowledge but also supportively improved their analytical, synthesis, communication, confidence and self-esteem of the students. The topic was discussed further, followed by presentation in detail as revision in brushing up the concepts and also clarifying the doubts immediately [7]. Thus, the method of learning through seminars is observed to be beneficial to the students to some extent as the efforts and enthusiasm is more in learning and presenting [8]. Unlike gigantic lecture where the students have to concentrate, listen and grasp the concepts without interaction which proves to be boring and teacher centric, seminar is one such learning tool wherein, the student enjoys the learning and gains knowledge as he/she plays a role of presenter, the scribe and the leader [9]. The student puts an effort of making his/her classmates to understand the concept that delivered in the seminar. Discussion followed by seminar helps in involving all the students and further clarifying the doubts raised after presentation. It is a need of time to consider the inclusion of seminars as a part of curriculum and one of the modes of learning for undergraduate students.

\section{Conclusion}

Majority of the students had given positive response to the seminars. The study recommends the inclusion of weekly seminars in the dental curriculum.

\section{References}

1. Lujan HL, DiCarlo SE (2006) First-year medical students prefer multiple learning styles. Adv Physiol Educ 30(1): 13-16.

2. Michael J (2007) What makes physiology hard for students to learn? Results of a faculty survey. Adv Physiol Educ 31(1): 34-40.

3. Henige $K$ (2012) Use of concept mapping in an undergraduate introductory exercise physiology course. Adv Physiol Educ 36(3): 197-206.

4. Gomathi KG, Shaafie IA, Venkatramana M (2014) Student-led seminars as a teaching-learning methodeffectiveness of a modified format. South East Asian J Med Educ 8(1): 82-84.

5. Spruijt A, Wolfhagen I, Bok H, Schuurmans E, Scherpbier A, et al. (2013) Teachers' perceptions of aspects affecting seminar learning: A qualitative study. BMC Med Educ 13: 22.

6. Rouse RA, Hamilton MA (1990) Dentists' technical competence, communication, and personality as predictors of dental patient anxiety. J Behav Med 13(3): 307-319.

7. Sondell K, Soderfeldt B (1997) Dentist-patient communication: a review of relevant models. Acta Odontol Scand 55(2): 116-126.

8. Yamalik N (2005) Dentist-patient relationship and quality care 3. Communication. Int Dent J 55(4): 254256.

9. Hannah A, Millichamp CJ, Ayers KM (2004) A communication skills course for undergraduate dental students. J Dent Educ 68(9): 970-977. 